ORIGINAL ARTICLE

\title{
Comparision of Infection Frequency in 1-Day Vs 5-Days Post Operative Antibiotic Regimen in Open Treated Facial Fractures
}

\author{
SYED TAHIR HUSAIN ${ }^{1}$, AHSAN ULLAH KHAN SHERANI ${ }^{2}$, SUNEEL KUMAR PUNJABI ${ }^{3}$, MONIS MANSOOR ALI ${ }^{4}$, \\ SHAHZAMAN MEMON ${ }^{5}$, RABIA ANIS ${ }^{6}$ \\ ${ }^{1} B D S$, FCPS, Senior RegistrarLiaquat National Hospital, Karachi \\ ${ }^{2}$ BDS, FCPS, Senior Registrar Department of Oral and Maxillofacial Surgery, IsraDental College/Hospital, Karachi \\ ${ }^{3}$ BDS, FCPS, Associate Professor, Oral and Maxillofacial Surgery DepartmentInstitute of DentistryLiaquat University of Medical \& Health \\ Sciences, Jamshoro \\ ${ }^{4}$ Dental Officer 2, Liaqat National Hospital, Karachi \\ ${ }^{5}$ Assistant Professor, Oral Pathology DepartmentBhitai Dental \& Medical College Mirpur Khas \\ ${ }^{6}$ Lecturer, Department of Oral and Maxillofacial Surgerylsra University Hyderabad \\ Corresponding Author:Dr. Syed Tahir Husain, E-mail: shahtahir51@yahoo.com, Phone: +92302 2964679
}

\begin{abstract}
Objective: To compare the frequency of surgical site infection by using postoperative prophylactic antibiotics (1day vs. > 5 days) in patients following open surgical reduction of facial fractures.

Design: Randomized Controlled Trial

Setting: Department of Dental \&Maxillofacial Surgery, Liaquat National Hospital, Institute of Postgraduate Medical Studies \& Health Sciences, Karachi.

Duration: 06months from 23 December 2016 to 22 June 2017.

Subject and Methods: A total of 368 cases according to inclusion and exclusion criteria were included in this study. Patients were randomly divided into two groups. Antibiotic (Inj. Augmentin 1.2g) was given to group A from admission to 24 hours postoperatively and in Group B antibiotic was continue up to 05 days postoperatively. A surgeon evaluated participants of both groups at 1,2, 3 and 4 weeks postoperatively for infection according to criteria of surgical site infection published by CDC. All information was noted in the proforma.

Results: - The average age of the patients was $31.10 \pm 7.39$ years. Rate of surgical site infection was not significant between groups ( $4.9 \%$ vs. $7.1 \% ; p=0.379)$.

Conclusion: In this study 1-day course of antibiotics postoperatively in facial fractures is as effective in preventing infective complications as a 5-day regimen. The use of prolonged postoperative antibiotics in uncomplicated facial fractures had no significant benefit in reducing the incidence of infections.
\end{abstract}

Key Words: Maxillofacial Surgeons, Surgical site infection, Prophylactic antibiotics

\section{INTRODUCTION}

Maxillofacial region is the most important area of the body, starting from the base of the skull to the hyoid bone, also the maxillofacial region is associated with systems such as visual, auditory, olfactory and speech. Disfiguring facial injuries can have severe psychological and social consequences [1]. Maxillofacial Surgeons are usually encountered by the fractures in facial region. The most common causes of maxillofacial region injuries determined by traffic accidents (49.01\%); fights (22.38\%) and fall injuries $(21.66 \%)^{[2]}$.Currently these fractures are treated by the open reduction and internal fixation (ORIF) for better stabilization, wound healing and esthetic outcomes. Both Extra-Oral and Intra-Oral approaches are used to reduce the fractured bones. These surgical wounds are usually considered as clean-contaminated wounds ${ }^{[3]}$ because there is inevitable contamination of these wounds with the bacterial flora of the oral cavity and nonsterile sinuses .However postoperative infection have become a common complication $^{[4]}$. Role of preoperative antibiotic prophylaxis has been supported by several studies and in their study, Chole and Yee showed that antibiotic administration 1 hour preoperatively decreases the infection rates significantly ${ }^{[5]}$

However, the role of postoperative antibiotics and their duration in facial fractures treatment remains unsettled and controversial. In literature antibiotic dose varies from single day ${ }^{[6,]}$ up to 07 or even 10 days postoperatively ${ }^{[7,8]}$. With the increasing rates of antibiotic resistance and calls for an evidence based approach to the patient care, clarifying the role of antibiotics use is important. Extensive antibiotics use may also be associated with several adverse effects, allergies, toxic reactions and drug reactions. It is important to get maximum treatment benefit while minimizing the development of resistance and other side effects. Therefore, antibiotics should be given for the shortest duration possible.

The misuse and overuse of even the critical drugs like antibiotics prevail worldwide to varying degrees ${ }^{[9]}$. Dietary habits (e.g. smoking and paangutka chewing), which have worse effect on wound healing ${ }^{[10]}$ are different in our population from western population where most studies were conducted and out of which few studies are in favor of prolong antibiotic use while other showed no difference in short term vs long term use in infection rates $(3 \% \text { \& } 7 \%)^{[6]}$,. The aim of my study is to compare the effect of 1 day vs 5 days postoperative antibiotics in prevention of surgical site infection, which may help to establish new protocols for prescribing postoperative antibiotic in our local population.

\section{MATERIALS AND METHODS}

This randomized controlled trial was conducted at Department of Dental \& Maxillofacial Surgery, Liaquat National Hospital, Institute of Postgraduate Medical Studies \& Health Sciences, Karachi for duration of06months from 23 December 2016 to 22 June 2017. 
Total 368 patients of either gender presented with the facial fractures diagnosed by the CT scan and Plain Radiographs, were selected for study. An informed and written consent was also taken from the patient or the attendant. Patient's ages were ranging between 18 to 45 years. ICU admitted patients, gunshot wounds (diagnosed by history, clinical exam), pathological fracture as a result of cysts,tumor or metastases(confirmed by history, clinical exam, radiograph), skull base fracture (confirmed by clinical exam and ct scans), allergy to penicillin, $\mathrm{HbA}_{1} \mathrm{c}>7.5$, $\mathrm{BMl}<17$, on immunosuppressant drugs (azathioprine, cyclosporine, corticosteroids), and post radiotherapy/chemotherapy patients were excluded.

Surgery was performed by senior(05 years experience) oral and maxillofacial surgeon. Both Extra-oral and Intra-oral incision approaches were used, as per requirement. Participants were divided into 2 groups: Group A and Group B, Antibiotic (Inj. Augmentin 1.2g) was given to group A from admission to 24 hours postoperatively and in Group B antibiotic was continue up to 05 days postoperatively. Surgeons evaluated participants of both groups at $1,2,3$ and 04 weeks postoperatively for infection according to criteria of surgical site infection published by CDC In case of infection, patients were treated with local measures including drainage, wound irrigation and antibiotic coverage as per bacterial culture report. The demographics information like age, gender, duration of fracture, type of fracture and the outcome variable infection was noted in the proforma attached as annexure.

Data was analyzed by using SPSS version 21 . Association of primary outcome (surgical site infection) with group A vs. group B was analyzed through Chi-Square. $P$ value $\leq 0.05$ was considered as significant.

\section{RESULTS}

Out of 368 cases, $270(73.4 \%)$ were males and $98(26.6 \%)$ were females. In group A and B $143(77.72 \%)$ and 127 $(69.02 \%)$ patients were males while $41(22.28 \%)$ and 57 $(30.98 \%)$ were females. Mean age of patients in group $A$ was $29.71 \pm 7.18$ and in group $B$ it was $32.48 \pm 7.36$. In group $A$ and $B, 84(45.7 \%)$ and $63(34.2 \%)$ patients were smokers, $114(62 \%)$ and $107(58.2 \%)$ patients were pan consumers, $73(39.7 \%)$ and $64(34.8 \%)$ patients were gutka user. (Table 1)
Table No 1: Baseline details of all the patients

\begin{tabular}{|l|l|l|}
\hline Variables & Group A & Group B \\
\hline Mean age (Yrs) & $29.71 \pm 7.18$ & $32.48 \pm 7.36$ \\
\hline Gender & $143(77.72 \%)$ & $127(69.02 \%)$ \\
\hline Male & $41(22.28 \%)$ & $57(30.98 \%)$ \\
\hline Female & $84(45.7 \%)$ & $63(34.2 \%)$ \\
\hline Dietry Habits & $114(62 \%)$ & $107(58.2 \%)$ \\
\hline Smoking & $73(39.7 \%)$ & $64(34.8 \%)$ \\
\hline Pan &
\end{tabular}

Most of diagnosis of fracture was zygomaticomaxillary Complex, 44\%, followed by lefort II, 31\%, Frontal bone fracture, $10.36 \%$, naso orbital ethmoidal fracture $9 \%$ and Lefort III, $5.7 \%$. Diagnoses with respect to groups are presented in figure 1.

Figure No 1: Type of Fracture of The Patients $n=368$

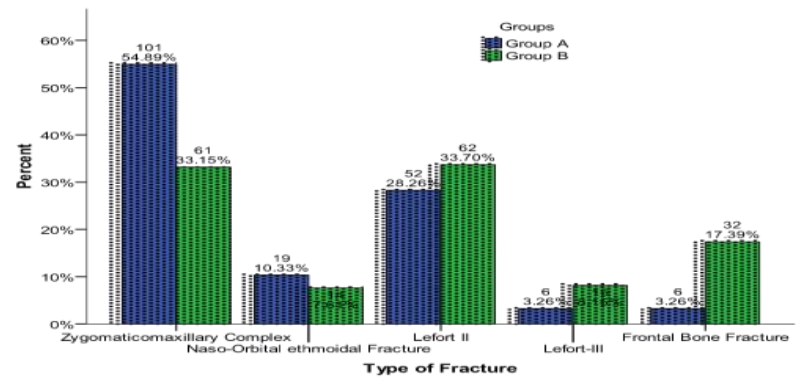

Rate of surgical site infection was not significant between groups $(4.9 \%$ vs. $7.1 \% ; p=0.379)$ as presented in table 2 .

Table No 2: Compare The Rate of Surgical Site Infection Between Groups

\begin{tabular}{|l|l|l|l|l|}
\hline Variables & Group A & Group B & Total & P-Value \\
\cline { 1 - 3 } $\begin{array}{l}\text { Surgical Site } \\
\text { Infection }\end{array}$ & \multicolumn{3}{|l}{0} \\
\cline { 1 - 4 } Yes & $9(4.9 \%)$ & $13(7.1 \%)$ & 22 & \\
\cline { 1 - 3 } NO & $175(95.1 \%)$ & $171(92.9 \%)$ & 346 & \\
\hline
\end{tabular}

When we stratified surgical site infection with types of fracture we found no significant difference between both groups ( $p$-value $>0.05$ ) except those who had frontal bone fracture with $p$-value $<0.05$. Table 3

Table No 3: Comparison of Surgical Site Infection Between Groups With Respect To Type of Fracture

\begin{tabular}{|c|c|c|c|c|}
\hline TYPE OF FRACTURE & $\begin{array}{l}\text { Outcome } \\
\text { [Surgical Site Infection] }\end{array}$ & $\begin{array}{l}\text { Group A } \\
n=184\end{array}$ & $\begin{array}{l}\text { Group B } \\
n=184\end{array}$ & P-Value \\
\hline Zygomaticomaxillary Complex & $\begin{array}{l}\text { Yes } \\
\text { No } \\
\text { Total }\end{array}$ & $\begin{array}{l}3(3 \%) \\
98(97 \%) \\
101\end{array}$ & $\begin{array}{l}3(4.9 \%) \\
58(95.1 \%) \\
61\end{array}$ & 0.673 \\
\hline Naso-Orbital ethmoidal Fracture & $\begin{array}{l}\text { Yes } \\
\text { No } \\
\text { Total }\end{array}$ & $\begin{array}{l}0(0 \%) \\
19(100 \%) \\
19\end{array}$ & $\begin{array}{l}3(21.4 \%) \\
11(78.6 \%) \\
14\end{array}$ & 0.067 \\
\hline Lefort II and III & $\begin{array}{l}\text { Yes } \\
\text { No } \\
\text { Total }\end{array}$ & $\begin{array}{l}3(5.2 \%) \\
55(94.8 \%) \\
58\end{array}$ & $\begin{array}{l}7(9.2 \%) \\
69(90.8 \%) \\
76\end{array}$ & 0.513 \\
\hline Frontal Bone Fracture & $\begin{array}{l}\text { Yes } \\
\text { No } \\
\text { Total }\end{array}$ & $\begin{array}{l}3(50 \%) \\
3(50 \%) \\
6\end{array}$ & $\begin{array}{l}0(0 \%) \\
32(100 \%) \\
32\end{array}$ & 0.002 \\
\hline
\end{tabular}




\section{DISCUSSION}

Bentley et al. ${ }^{[86]}$ found a statistically significant difference in the rate of infection between patients who received only 1 day of postoperative antibiotics $(60 \%)$ compared with those receiving 5 days of antibiotics $(6.7 \%)$, which contrasts with the findings of others who found no difference. ${ }^{[11,12]}$

In present study age distribution of the patients is presented in figure 1. The average age of the patients was $31.10 \pm 7.39$ years. Out of 368 cases, 270(73.4\%) were male and 98(26.6\%) were female. In Mottini et al study ${ }^{[13]}$ there were 253 males and 86 females, with an average age of 42.8 years (range, 16-90 years) at the time of trauma and a combined total of 498 fractures between them. In Zixet al study [6] there were 39 men and 21 women, mean age (range) 42 (13-92) years.

In present study most of diagnosis of fracture was zygomaticomaxillary Complex, 44\%, followed by lefort II, $31 \%$, Frontal bone fracture, $10.36 \%$, naso orbital ethmoidal fracture $9 \%$ and Lefort III, 5.7\%. In Mottini et al study ${ }^{[13]}$ zygomatic fractures accounted for the largest percentage (42.37\%), followed by orbital floor (33.53\%) and mandibular fractures $(23.09 \%)$. In comparison, there were only few Le Fort type fractures (1.0\%). A large-scale craniomaxillofacial trauma review performed by Gassneret al., ${ }^{[14]}$ with midface fractures making up more than $70 \%$ of all fractures, mandible fractures approximately $25 \%$, and a much smaller percentage of Le Fort type fractures.

Dietary habits (e.g. smoking and paangutka chewing), which have worse effect on wound healing ${ }^{[10]}$ are different in our population from western population where most studies were conducted and out of which few studies are in favor of prolong antibiotic use while other showed no difference in short term vs long term use in infection rates $(3 \% \& 7 \%)^{[6]}$.

In present study rate of surgical site infection was not significant between groups $(4.9 \%$ vs. $7.1 \% ; p=0.379)$. Similar result was also reported in Mottini et al study ${ }^{[13]}$.We found no significant difference between the groups in the wound infection rate, which indicated that antibiotic prophylaxis for more then $24 \mathrm{~h}$ postoperatively does not contribute to the prevention of postoperative infections. All patients with postoperative infections developed superficial infections in the infra orbital region where they had contaminated lacerations of the soft tissue, so these infections may not have been related to the operation.

The general use of prophylactic antibiotics after trauma to the orbit is controversial ${ }^{[15-18]}$ and there are still no clear guidelines. While there seems to be a consensus that antibiotic prophylaxis should be used to prevent devastating postoperative infections in displaced orbital fractures, the duration of the course remains unclear. Some authors advise prescription of antibiotics routinely in all cases of orbital fractures, ${ }^{[15]}$ others limit the use of a prophylactic antimicrobial to cases that require open reduction, orbital emphysema, and open fractures. ${ }^{[17]}$ In a survey by Courtney et al. in which 187 practicing fellows of the British Association of Oral and Maxillofacial Surgeons were interviewed, almost all surgeons (91\%) stated that they used prophylactic antibiotics routinely for orbital fractures. ${ }^{[15]}$ The study also showed that there was no consensus about the start and duration of prophylaxis.
While $47 \%$ of the surgeons interviewed started prophylactic treatment at the time of diagnosis, $53 \%$ started it at induction of anaesthesia. The duration of postoperative prophylaxis varied between nil $(9 \%)$ and up to more than 7 days (19\%). Most surgeons (63\%) gave antibiotics for 5 days postoperatively.

\section{CONCLUSION}

In this study in facial fractures 1-day course of antibiotics postoperatively is as effective in preventing infective complications as a 5-day regimen. The use of prolonged postoperative antibiotics in uncomplicated facial fractures had no significant benefit in reducing the incidence of infections.

\section{REFERENCES}

1. Borah GL, Rankin MK. Appearance is a function of the face. PlastReconstr Surg 2010;125:873-75.

2. Pandey S, Roychoudhury A, Bhutia O, Singhal M, Sagar S, Pandey RM.Study of the pattern of maxillofacialfracturesseen at a tertiary care hospital in north India. J'Maxillofac Oral Surg. 2015 Mar;14(1):32-39.

3. VakadeCD,Rai KK, Shiva Kumar HR, Batra J. Efficacy of postoperative antibiotics in the management of facial fractures: single day against five day regimen. Arch CranOroFacSc 2014;1(6):76-80.

4. Schaefer EH, Caterson IV EJ. Antibiotic selection for open reduction internal fixation of mandible fractures. J Craniofac Surg 2013;24:858.

5. Chole RA, Yee J. Antibiotic prophylaxis for facial fractures. A prospective, randomized clinical trial. Arch. Otolaryngol. Head Neck Surg.1987;113:1055-7.

6. Zix J, Schaller B, Izuka T, Leiger O. The role of postoperative prophylactic antibiotics in the treatment of facial fractures: a randomized, double-blind, placebo-controlled pilot clinical study. Part 1: orbial fractures in 62 patients. $\mathrm{Br} \mathrm{J}$ Oral Maxillofac Surg. 2012;52:332-36

7. Knepil GJ, Loukota RA. Outcomes of prophylactic antibiotics following surgery for zygomatic bone fractures. J Craniomaxillofac Surg. 2010;38(2):131-33.

8. Bui $\mathrm{P}$, Demian $\mathrm{N}$, Beetar $\mathrm{P}$. Infection Rate in mandibular angle fractures treated with a $2.0-\mathrm{mm}$ 8-hole curved strut plate. J Oral Maxillofac Surg. 2009;67(4):804-08

9. Holloway K, Dijk LV. The world medicines situation 2011. Rationa use of medicines. 3rd ed, World Health Organization Geneva 2011.

10. George PY, Michael TL. Abstinence From Smoking Reduces Incisional Wound Infection. Ann Surg. 2003;238(1): 6-8.

11. Peterson LJ, Booth DF. Efficacy of antibiotic prophylaxis in intraoral orthognathic surgery. J Oral Surg. 1976;34(12):1088-91.

12. Ruggles JE, Hann JR. Antibiotic prophylaxis in intraoral orthognathic surgery. J Oral Maxillofac Surg. 1984;42(12):797-801.

13. Mottini M, Wolf R, Soong PL, Lieger O, Nakahara K, and Schaller B. The role of postoperative antibiotics in facial fractures: Comparing the efficacy of a 1-day versus a prolonged regimen. J Trauma Acute Care Surg. 2014;76:720-24

14. Gassner R, Tuli T, Ha"chl O, Rudisch A, Ulmer H. Craniomaxillofacial trauma: a 10 year review of 9,543 cases with 21,067 injuries. J Craniomaxillofac Surg. 2003;31(1):51-61.

15. Courtney DJ, Thomas $\mathrm{S}$, Whitfield $\mathrm{PH}$. Isolated orbital blowout fractures:survey and review. Br J Oral Maxillofac Surg 2000;38:496504

16. Shuttleworth GN, David DB, Potts MJ, Bell CN, Guest PG. Lesson of the week: orbital trauma. Do not blow your nose. BMJ 1999;318:1054-5

17. Newlands C, Baggs PR, Kendrick R. Orbital trauma. Antibiotic prophylaxis needs to be given only in certain circumstances. BMJ. 1999;319:516-7.

18. Westfall CT, Shore JW. Isolated fractures of the orbital floor: risk of infection and the role of antibiotic prophylaxis. Ophthalmic Surg. $1991 ; 22: 409-11$. 